\title{
Performance analysis of patch antenna for underwater wireless communication in seawater
}

\author{
Siti Harliza Mohd Razali ${ }^{1}$, Razali Ngah ${ }^{2}$, Yoshihide Yamada ${ }^{3}$, Kamilia Kamardin ${ }^{4}$ \\ ${ }^{1,2}$ Wireless Communication Centre, School of Electrical Engineering, Faculty of Engineering, Universiti Teknologi \\ Malaysia, 81310 Skudai, Johor Bahru, Johor, Malaysia \\ ${ }^{3,4}$ Communication System and Network Research Lab, Malaysian-Japan International Institute of Technology (MJIIT), \\ Universiti Teknologi Malaysia, Jalan Sultan Yahya Petra, 54100 Kuala Lumpur, Malaysia
}

\begin{tabular}{|c|c|}
\hline Article Info & ABSTRACT \\
\hline Article history: & \multirow{10}{*}{$\begin{array}{l}\text { Underwater wireless communication in seawater is becoming more } \\
\text { interesting and challenging in recent years. The development of antenna for } \\
\text { underwater wireless communication in seawater at } 900 \mathrm{MHz} \text { UHF range } \\
\text { frequency is implemented by using patch antenna. In this paper, the antennas } \\
\text { were designed using FEKO, an electromagnetic simulation software, and a } \\
\text { suitable size for rectangular patch antenna for seawater application was } \\
\text { developed to study the relevance between } \lambda \text { o with } W \text { and } L \text { in seawater. The } \\
\text { major difference between the patches in free space and seawater was the } \\
\text { feedpoint distance for antenna. For } L \text { size, which was slightly bigger, about } \\
0.9 \text { mm than free space size can consider almost same. But the gain for patch } \\
\text { antenna in seawater was found at }-2.51 \mathrm{dBi} \text {, lower than patch antenna in free } \\
\text { space, which was } 5.76 \text { dBi due to the path loss in seawater. This shows that } \\
\text { attenuation happened, and a better antenna will be design. The one that has } \\
\text { better gain, which is around above } 2 \mathrm{dBi} \text { in seawater, in order to get better } \\
\text { performance antenna in seawater environment. }\end{array}$} \\
\hline Received Jul 22, 2020 & \\
\hline Revised Dec 10, 2020 & \\
\hline Accepted Mar 9, 2021 & \\
\hline Keywords: & \\
\hline Antenna design method & \\
\hline Device to device & \\
\hline Patch antenna & \\
\hline Seawater antenna & \\
\hline UHF & \\
\hline
\end{tabular}

This is an open access article under the CC BY-SA license.

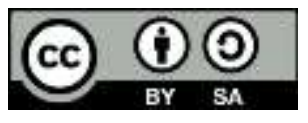

\section{Corresponding Author:}

Siti Harliza Mohd Razali

Wireless Communication Centre, School of Electrical Engineering

Faculty of Engineering, Universiti Teknologi Malaysia

81310 Skudai, Johor Bahru, Johor, Malaysia

Email: sharliza.poli@gmail.com, s.harliza@graduates.utm.my

\section{INTRODUCTION}

Underwater wireless communication in seawater becomes more interesting because of research in aquatic environment is growing day by day. There are acoustic, free space optical and electromagnetic radio frequency applications that are involved in aquatic environment. This paper will concentrate on the use of electromagnetic radio frequency in designing a patch antenna. The proposed antenna is designed at $900 \mathrm{MHz}$ licensed band for device-to-device underwater in seawater application especially for diver use.

The major issue of this study is that underwater communications have been limited in distance due the high attenuation for seawater RF communication frequencies. Although reliable RF communication distance is only a few meters, the main advantage of RF is that it can cross water and air surface borders, and this is significant [1]-[3]. This study is important in multiplying the selection of antenna types that can be applied in seawater, and to choose the best one for a particular application because ocean technology is growing in underwater communications because of its varied applications such as in marine research, oceanography, marine commercial operations, offshore oil industry, defense and leisure [3]. Compared to the initial communication system, sustained research over the years has resulted in better performance and 
sturdiness in underwater communication, which resulted in many communication products for use in water being available today.

There are several previous works that present similar application as this paper but with different types of antenna and frequency. In [4], they used a loop antenna with a diameter of $16 \mathrm{~cm}$ with a performance of S11 $39 \mathrm{MHz}$, while gain was not mentioned. In [5], they used dipole antennas with parasitic elements with sizes ranging from $82 \mathrm{~mm}$ to $475 \mathrm{~mm}$, and the performances were $65 \mathrm{MHz}$ for bandwidth, and $25 \mathrm{MHz}$ and $40 \mathrm{MHz}$ for gain. Furthermore, in [6] loop, dipole and J-pole antennas were used with sizes around 74.55 $\mathrm{mm}, 115.50 \mathrm{~mm}$ and $121.80 \mathrm{~mm}$ for $40 \mathrm{MHz}$, which had bandwidth performances of $13.94 \mathrm{MHz}, 11.89 \mathrm{MHz}$ and $10.43 \mathrm{MHz}$. While in [7], they used 3 types of loop antennas with ground plane for 40 to $100 \mathrm{MHz}$ resonance, and the size were around $130 \mathrm{~mm}$ to $400 \mathrm{~mm}$ that gave directivity from 13 to $19 \mathrm{~dB}$. In [8], a bow-tie antenna was used for dual band at 2.4 and $5.1 \mathrm{GHz}$ with a size of around $11 \mathrm{~mm}$ to $12 \mathrm{~mm}$, and the maximum gain achieved was $1.2 \mathrm{dBi}$ at $\theta=0$, and a variable received power of -71 to $-64 \mathrm{dBm}$. And in [9], half wave dipole antenna of $33.37 \mathrm{~cm}$ long at $30 \mathrm{kHz}$ obtained attenuation in seawater at $6.54 \mathrm{~dB} / \mathrm{m}$. The novelty of this study is frequency and measured permittivity value was used for antenna performance. Creativity is about the relationship between the antenna gain and antenna loss propagation with the depth of this paper is the full analysis of antenna performance between free space and seawater.

All previous works mentioned above did not provide complete antenna performances and just discussed several performances. A problem that will be solved in this paper is how to design a rectangular patch antenna with good antenna performance as a free space one. The reasons of comparison study between free space and seawater propagation is to study how the differences of the patch antenna size between free space and seawater and other characteristics that involve in developing seawater antenna for RF communication. In this paper, the probability of the development of patch antenna in seawater was studied to determine the suitable size and to get best antenna performance. This paper is organized as the following. Section 2 is the theoretical part, simulation and antenna performance, Section 3 is the discussion, and Section 4 will conclude the paper.

\section{FUNDAMENTAL KNOWLEDGE (THEORETICAL PART)}

\subsection{Patch antenna design in free space}

The rectangular patch antenna for free space was designed using formula (1), which is the basic formula to find $L$ value that suitable for operational frequency and material used. In (2) Estimates the value of width for that patch antenna (3) and (4) are extended formulas for the better size designs of patch antenna [10]. By using all the formula, it is easy to start designing the model in Feko using the calculated size.

$$
\begin{gathered}
L=0.49 \lambda_{g}=0.49\left(\frac{\lambda}{\sqrt{\varepsilon}}\right) \\
\text { Width }=\frac{c}{2 f_{0} \sqrt{\frac{\varepsilon_{r}+1}{2}}}
\end{gathered}
$$

$$
\varepsilon_{e f f}=\frac{\varepsilon_{r}+1}{2}+\frac{\varepsilon_{r}-1}{2}\left[\frac{1}{\sqrt{1+12\left(\frac{h}{W}\right)}}\right]
$$

$$
\text { Length }=\frac{c}{2 f_{0} \sqrt{\varepsilon_{\text {eff }}}}-0.824 h\left(\frac{\left(\varepsilon_{\text {eff }}+0.3\right)\left(\frac{W}{h}+0.264\right)}{\left(\varepsilon_{\text {eff }}-0.258\right)\left(\frac{W}{h}+0.8\right)}\right)
$$

The patch antenna was fitted to the class of resonant quatiantennas, then its resonant behavior was responsible for the main challenge in patch antenna adequate bandwidth, which is conventional patch designs 
that produced bandwidths as low as a few percent [10]. To develop a design of a suitable patch antenna, length and width were calculated using the formulas (1), (2), (3) and (4) is shown in Figure 1(i).

The two ends of the patch that were connected to, and opposite from, the feed connection provided the radiation, acting as slot antennas, where each slot is the gap between the ends of the patch and the ground plane beneath the dominant dielectric layer [10]. The arrows on the left and right ends of the patch represent the currents between the patch conductor and ground plane as shown in Figure 1(ii). At the ends, where they were not contained, these currents resulted in the desired radiation of electromagnetic waves from the two end slots. The microstrip feedline excited the centre of the slot formed by the end of patch that to which it was connected. Between the underside of the patch and the substrate ground place, a low impedance transmission line was formed that subsequently fed the slot on the opposite side [10]. There are also have another patch antenna type but not apply yet in seawater. The previous work was dielectric dense patch antenna applied in zamzam water [11], P-shape patch antenna applied for radar, mobile and others wireless communication [12] and monopole patch antenna for ultra-wideband (UWB) application [13]. Future research to use these previous work antennas and apply it in seawater to find the new gain that antenna will obtain.

The parameters used in simulation for free space were tabled as in Table 1. Figure 2(i) shows the value of frequency $901 \mathrm{MHz}$ when the input impedance is $50 \Omega$ and that also obtained the electric field as Figure 1(ii) as the fundamental resonance was achieved. It means the balance amplitude on $L$ side, and the antenna can be considered as a $\lambda / 2$ transmission line resonant cavity with two open ends where the fringing fields from the patch to the ground are exposed to the upper half space $(\mathrm{z}>0)$ and are responsible for the radiation [10]. The gain obtained is $5.76 \mathrm{dBi}$ as in $3 \mathrm{D}$ view. $\mathrm{S} 11$ or return loss is $-24.2 \mathrm{~dB}$ at $900.26 \mathrm{MHz}$ and the bandwidth is $5.71 \mathrm{MHz}$. All performances for the free space antenna were obtained as theoretical results.

Table 1. Simulation parameters in a free space

\begin{tabular}{lll}
\hline \multicolumn{1}{c}{ Aspect } & \multicolumn{2}{c}{ Parameter } \\
\hline Simulator & Altair FEKO 2019 & Method of Moment \\
Frequency & UHF & $900 \mathrm{MHz}$ \\
& Length $\left(\mathrm{L}_{0}\right)$ & $101 \mathrm{~mm}$ \\
Antenna & Width $\left(\mathrm{W}_{0}\right)$ & $120 \mathrm{~mm}$ \\
& Height of substrate $(\mathrm{h})$ & $1.524 \mathrm{~mm}$ \\
& Feedpin from origin & $19.5 \mathrm{~mm}$ \\
& Permittivity, $\varepsilon_{\mathrm{r}}$ & 2.55 \\
Dielectric (Arlon) $)$ & Conductivity, $\sigma$ & $0 \mathrm{~S} / \mathrm{m}$ \\
& Tan $\delta$ & 0.0018 \\
& Mesh size, $\Delta m$ & $\lambda 16$ \\
\hline
\end{tabular}

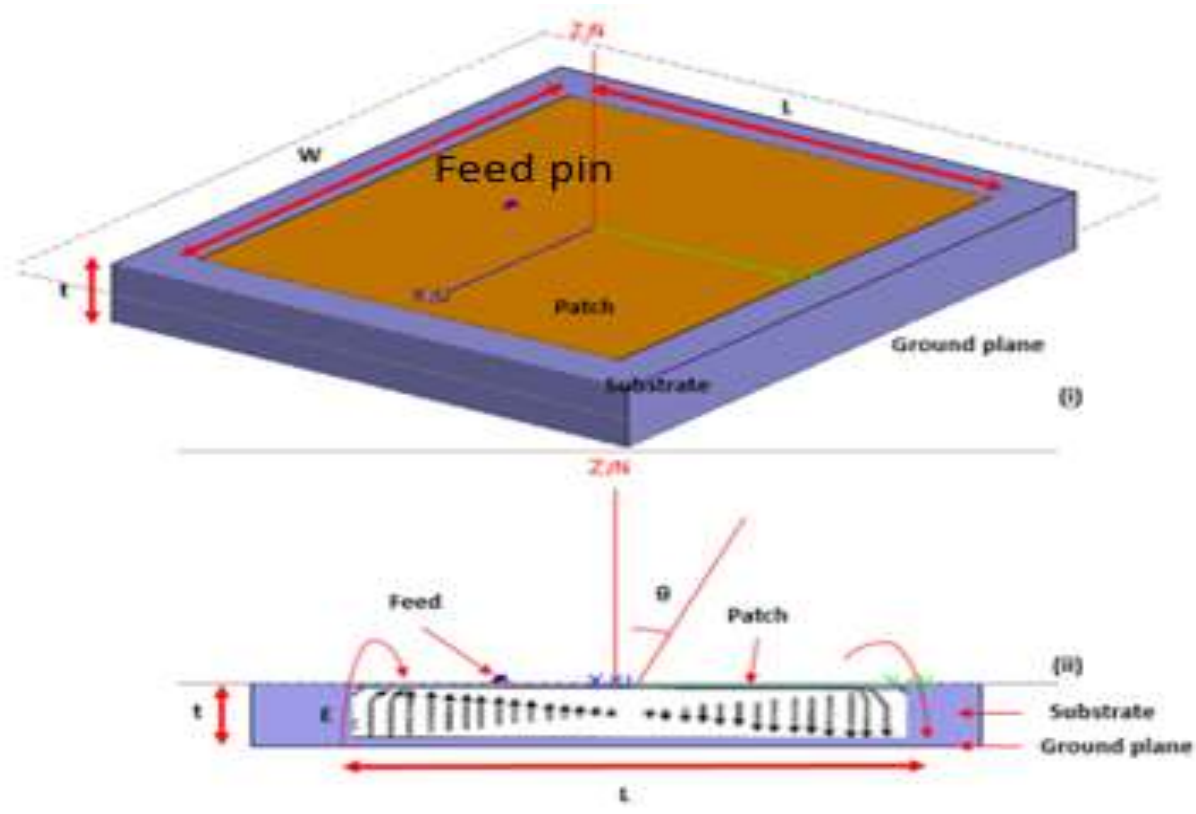

Figure 1. (i) geometry for analyzing the edge-fed microstrip patch antenna, (ii) side view showing the electric fields in free space environment 
(i)

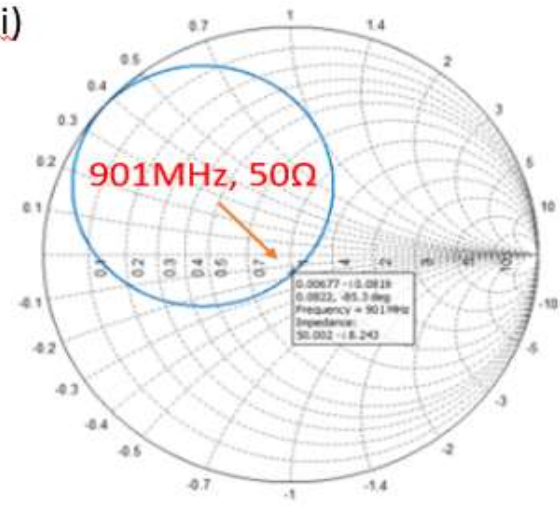

(ii)

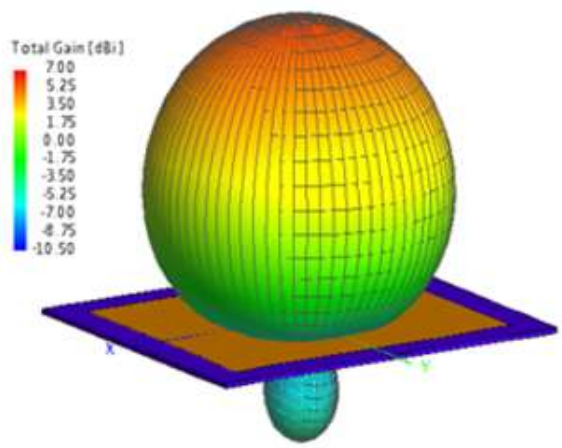

Figure 2. (i) Input impedance for patch antenna in free space; (ii) Radiation pattern for patch antenna in free space for 3D view

\subsection{Measurement of electric constants in seawater}

Before the simulation in seawater was implemented, the process of measuring permittivity for seawater was performed by using a PNA device (network analyzer), setup with calibration of distilled water permittivity. Then, when the result was accurate (nearly 80), usually around 77 to 79 , the measure of seawater permittivity was executed. There were 3 samples of seawater involved, as stated in Table 2 . The process of measurement is shown as in Figure 3(i) and 3(ii). The relative permittivity $\left(\varepsilon_{\mathrm{r}}\right)$ of water depends on several factors like water temperature, salinity and propagation frequency [14], and it can be described by the Debye model [15]-[16] or by the Cole-Cole equation [17]. For this simulation the permittivity and conductivity value used were 58.91 and $0.32 \mathrm{~S} / \mathrm{m}$, which were chosen from measured values from Table 2 as the value is the highest. Conductivity was calculated using formula $\sigma=\omega \varepsilon_{0} \varepsilon^{\prime} \tan \delta$ where $\varepsilon_{0}=$ $8.85 \times 10^{-12} \mathrm{~F} / \mathrm{m}[18]$.

Table 2. Measured permittivity value of seawater

\begin{tabular}{|c|c|c|c|c|c|c|c|c|c|c|}
\hline \multirow{3}{*}{$\begin{array}{l}\text { Frequency }(\mathrm{MHz}) \\
\text { Name of Beach }\end{array}$} & \multirow[b]{3}{*}{ Parameter } & \multirow[b]{3}{*}{$\varepsilon^{\prime}$} & \multicolumn{2}{|l|}{400} & \multicolumn{3}{|c|}{900} & \multicolumn{3}{|c|}{1500} \\
\hline & & & & & & & & & & \\
\hline & & & $\varepsilon^{\prime \prime}$ & $\sigma$ & $\varepsilon^{\prime}$ & $\varepsilon^{\prime \prime}$ & $\sigma$ & $\varepsilon^{\prime}$ & $\varepsilon^{\prime \prime}$ & $\sigma$ \\
\hline Batu Feringgi Beach, Penang & & 54.47 & -4.61 & 0.11 & 58.91 & -7.11 & 0.32 & 63.73 & -7.18 & 0.56 \\
\hline Klebang Beach, Melaka & & 49.26 & 7.38 & 0.17 & 56.87 & -1.36 & 0.06 & 62.56 & -4.12 & 0.32 \\
\hline Remis Beach, Selangor & & 39.78 & -5.67 & 0.13 & 44.30 & -9.53 & 0.43 & 50.08 & -12.03 & 0.94 \\
\hline
\end{tabular}

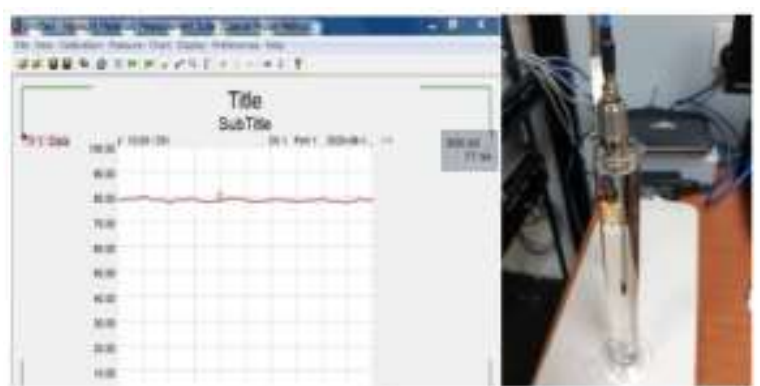

(i)

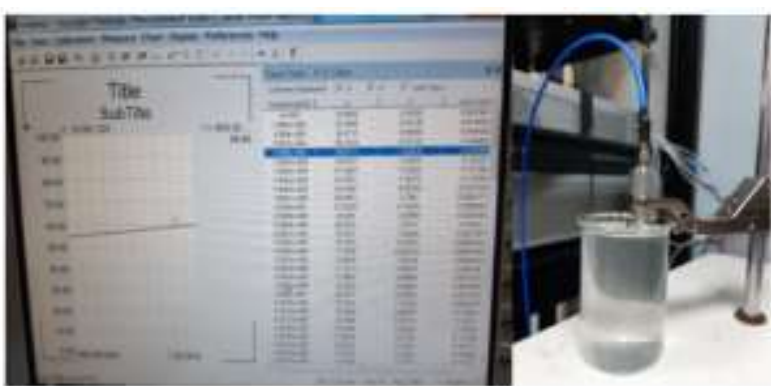

(ii)

Figure 3. (i) Calibration process; (ii) Process of measuring the value of seawater permittivity

\subsection{Simulation of patch antenna in seawater}

A challenge in this paper was to find the suitable patch size when placed in seawater because the size of seawater patch antenna cannot be calculated using formulas (1) to (4). So in order to find a solution, a 
process of trial and error was implemented to get the S11 needed. Firstly, the free patch size was referred to as the starting patch size. Then, the size was changed little by little, by its $L$ size and $W$ size, to get the actual size of S11 $900 \mathrm{MHz}$. This frequency was selected because it is within the UHF band class that is suitable to extend the distance between antennas when in seawater. In [19], the advantages of electromagnetic radio frequency were many times compared to acoustic and free space optical but the disadvantage is that it has severely limited range in water. The purpose of this paper is to study the importance of developing an antenna in seawater and analyze the performances of the antenna.

This paper is different from others because it concentrates on the theoretical part of development of the rectangular patch antenna in seawater. Others concentrated more on immersed coated loop antenna [20], loop and vibrator antenna [21], dipole antenna [2], loop and dipole antenna [3], loop antenna with ground plane [4], bow-tie antenna [5, 22], half dipole antenna [9] and wideband microstrip circular patch antenna with buffer layer [23]. And [24] is concentrate on underwater antennas and measuring wave propagation in the sea ice and the sea water. The differences of these two antennas were analyzed by their $\lambda g$. This paper will discuss further two cases of patch antenna in free space and in seawater with the same operating frequency.The parameters of simulation were tabled as in Table 3 and the design of the antenna is shown in Figure 4.

Table 3. Simulation parameters in seawater

\begin{tabular}{lll}
\hline Aspect & \multicolumn{2}{c}{ Parameter } \\
\hline Simulator & Altair FEKO 2019 & Method of Moment \\
Frequency & UHF & $900 \mathrm{MHz}$ \\
Antenna & Length $\left(\mathrm{L}_{\mathrm{s}}\right)$ & $101.9 \mathrm{~mm}$ \\
& Width $\left(\mathrm{W}_{\mathrm{s}}\right)$ & $120 \mathrm{~mm}$ \\
& Height of substrate $(\mathrm{h})$ & $1.524 \mathrm{~mm}$ \\
& Feedpin from origin & $49.1 \mathrm{~mm}$ \\
Dielectric (Arlon) & Permittivity, $\varepsilon_{\mathrm{r}}$ & 2.55 \\
& Conductivity, $\sigma$ & $0 \mathrm{~S} / \mathrm{m}$ \\
& Tan $\delta$ & 0.0018 \\
& Mesh size, $\Delta m$ & $\lambda 16$ \\
Dielectric (Seawater) & Length of seawater & $181.9 \mathrm{~mm}$ \\
& Width of seawater & $200 \mathrm{~mm}$ \\
& Height of seawater & $82.524 \mathrm{~mm}$ \\
& Permittivity, $\varepsilon_{\mathrm{r}}$ & 58.91 \\
& Conductivity, $\sigma$ & $0.32 \mathrm{~S} / \mathrm{m}$ \\
& Mesh size, $\Delta m$ & $\lambda 16$ \\
& Air gap & $10 \mathrm{~mm}(5 \mathrm{~mm}+5 \mathrm{~mm})$ \\
\hline
\end{tabular}

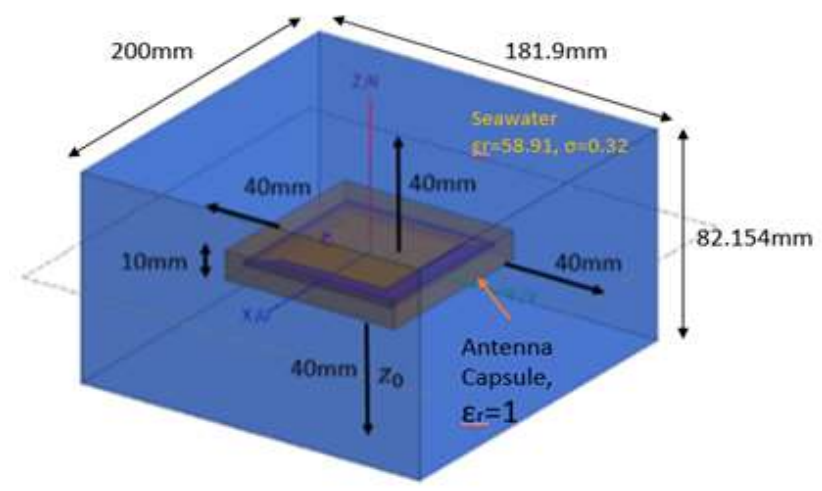

Figure 4. Simulation model of patch antenna in seawater in 3D view

The patch antenna in seawater was designed by changing its $L$ size bit by bit to obtain the suitable size that can have a resonance at $900 \mathrm{MHz}$. Figure 5(i) shows the electric field that was obtained for this case. It shows that the electric field distribution is the same as the fundamental mode resonance as in Figure 1 (ii). Thus, the patch antenna in seawater was judged to be working well in seawater. Meanwhile, Figure 5(ii)

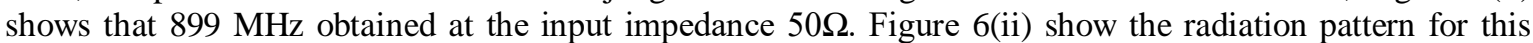
case, where the main lobe is $-2.51 \mathrm{dBi}$. S11 for this case is -26.54 at $900.57 \mathrm{MHz}$ and the bandwidth obtained was $16.53 \mathrm{MHz}$, which is bigger than the free space bandwidth value. 
(i)

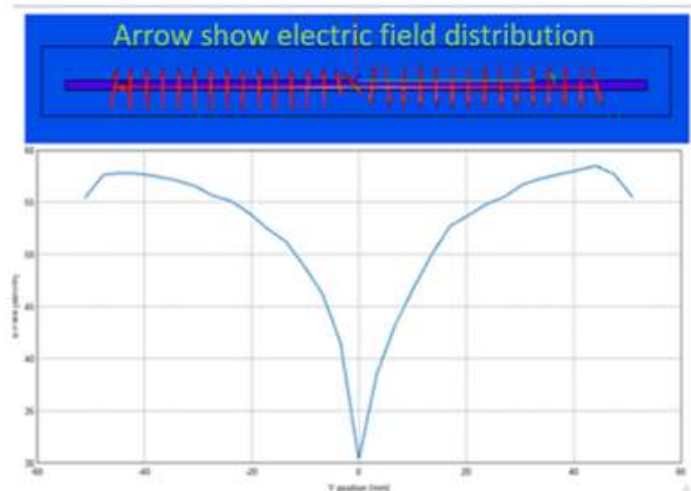

(ii)

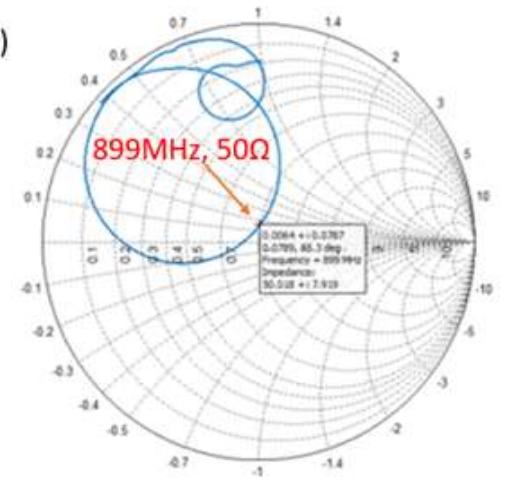

Figure 5. (i) Patch antenna in seawater with electric field result; (ii) input impedance for patch antenna in seawater

(i)

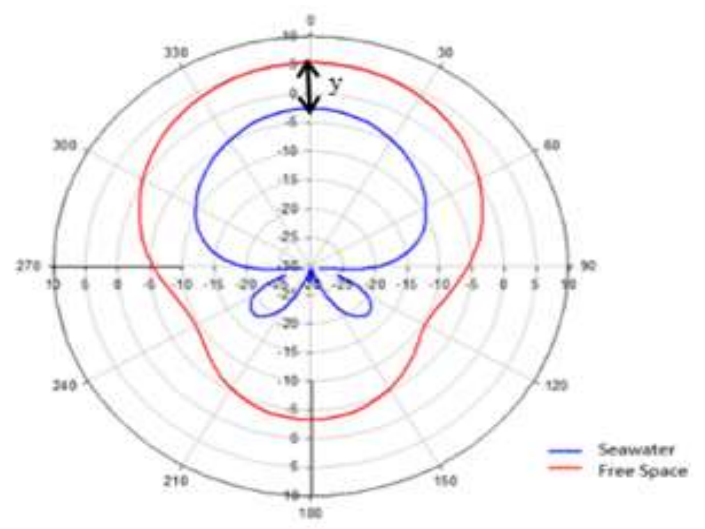

(ii)

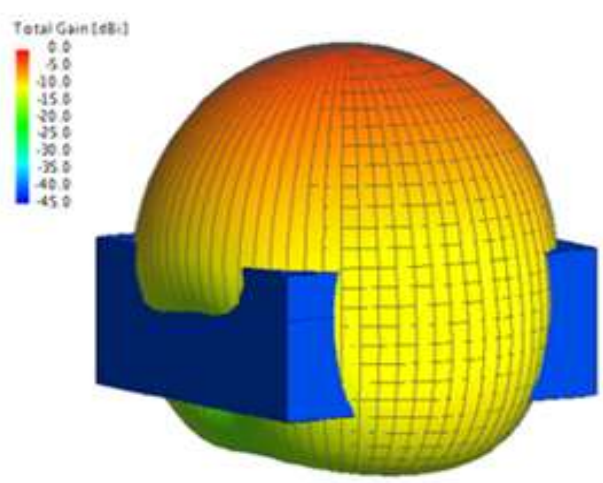

Figure 6. (i) Difference gain between patch antenna in free space and seawater. (ii) 3D view radiation pattern for patch antenna in seawater

\section{PERFORMANCE ANALYSIS}

\subsection{Change of antenna radiation}

Table 4 shows, size of patch antenna in seawater was slightly larger than the one in free space but can consider as no change because the difference is only $0.9 \mathrm{~mm}$. The position of the feed pin depended on the size of $L$ and its proximity to the edge of $L$. Thus the difference of feed pin location between them is about $29.6 \mathrm{~mm}$. Besides that, for seawater the bandwidth was larger than the bandwidth in free space. The gain value in seawater was also found to have attenuated from the gain value in free space. Furthermore, the depth of seawater affected the resonance to get the operational frequency. The deeper the seawater, the bigger the $L$ size. Future research will need to design a suitable patch that can obtain the gain or radiation pattern that equals $2 \mathrm{dBi}$ and above to fulfil the best antenna requirement for diver's tool application. There are many $\mathrm{RF}$ frequencies that give less attenuation in certain conditions such as in fresh and river water conditions, which is EM out performs acoustics in terms of bandwidth [25].

Table 4. Comparison between free space and seawater

\begin{tabular}{lcc}
\hline \multicolumn{1}{c}{ Aspect } & Free Space & Seawater \\
\hline Permittivity used $(\varepsilon)$ & 1 & 58.91 \\
Conductivity used $(\sigma)$ & 0 & 0.32 \\
Lambda $\mathrm{g}, \lambda_{\mathrm{g}}=\mathrm{c} /[(\sqrt{\varepsilon})(900 \mathrm{MHz})]$ & $208.74 \mathrm{~mm}$ & $43.42 \mathrm{~mm} \sim 40 \mathrm{~mm}$ \\
Feed pin & $19.5 \mathrm{~mm}$ & $49.1 \mathrm{~mm}$ \\
S11 & $-24.20 \mathrm{~dB}$ at $900.26 \mathrm{MHz}$ & $-26.54 \mathrm{~dB}$ at $900.57 \mathrm{MHz}$ \\
Input impedance $(50 \Omega)$ & At $901 \mathrm{MHz}$ & At $899 \mathrm{MHz}$ \\
Bandwidth & $5.71 \mathrm{MHz}$ & $16.53 \mathrm{MHz}$ \\
Gain & $5.76 \mathrm{dBi}$ & $-2.51 \mathrm{dBi}$ \\
\hline
\end{tabular}




\subsection{Propagation loss}

Propagation of signal causes losses. These losses can be an estimation by calculating the electric field degradation. The complex propagation constant is (5). Thus, the value of attenuation constant, $\alpha$ is needed and expression (6) shows how to calculate the value. Hence, electric field degradation, $\mathrm{L}_{\mathrm{z}}$ can be calculated by using (7), and $\mathrm{z}$ represents the travelled distance of the signal.

Figure 7(ii) above shows that the loss in seawater at $\mathrm{z}=0.04 \mathrm{~m}(40 \mathrm{~mm})$, as calculated by using the theory formula, was about $-2.73 \mathrm{~dB}$. But as the $\mathrm{y}$ in Figure 6(i) shows, the difference between free space antenna gain and seawater antenna gain (attenuation/ loss) was about $8.27 \mathrm{dBi}$. The difference is $5.54 \mathrm{~dB}$ can assume as path loss for $40 \mathrm{~mm}$ distance. So the gain from the link budget equation, received power $(\mathrm{dB})=$ transmitted power $(\mathrm{dB})+$ Gains $(\mathrm{dB})$ - losses $(\mathrm{dB})$ must be considered to develop the new antenna design that will obtain a high gain, which ultimately will improve the loss of $8.27 \mathrm{dBi}$ as mentioned before.

$$
\begin{aligned}
\gamma & =\alpha+\mathrm{j} \beta \\
\alpha & =\sqrt{\frac{\omega^{2} \varepsilon \mu_{0}}{2}} \sqrt{\sqrt{1+\left(\frac{\sigma}{\omega \varepsilon}\right)^{2}}-1} \\
\mathrm{~L}_{\mathrm{z}} & =10 \log \mathrm{e}^{-2 \alpha \mathrm{z}}
\end{aligned}
$$

(i)

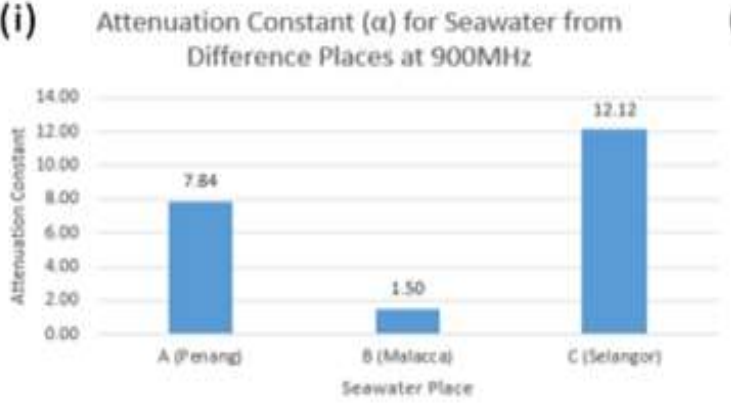

(ii)

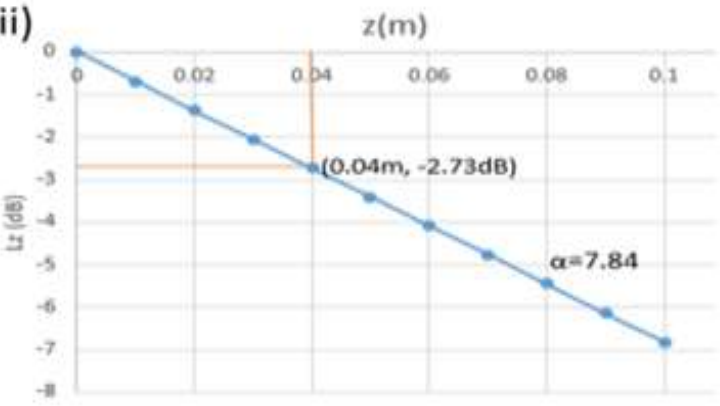

Figure 7. (i) $\alpha$ value of seawater (In (6)); (ii) Propagation loss ( $\mathrm{L}_{\mathrm{Z}}$ ) change of seawater (At (7))

\section{CONCLUSION}

The performance of patch antenna in seawater obtained was as expected, which is the antenna in seawater can give more bandwidth than the free space one. Also, the size of the patch in seawater was successfully obtained, which in theory, achieved similar radiation pattern as that of in free space with a slight attenuation. The size of antenna is considering same but the major difference is feedpin location of the antenna. For future research, a new antenna design needs to be built to increase the gain in seawater.

\section{ACKNOWLEDGEMENTS}

This work was supported by the ministry of higher education (MOHE) in Malaysia and Universiti Teknologi Malaysia (UTM) through the fundamental research grant scheme (FRGS) under Grant R. J130000.7823.4F965. The Grant is managed by the research management centre (RMC) at UTM.

\section{REFERENCES}

[1] K. M. Awan, P. A. Shah, K. Iqbal, S. Gillani, W. Ahmad, and Y. Nam, "Underwater Wireless Sensor Networks: A Review of Recent Issues and Challenges," Wirel. Commun. Mob. Comput., vol. 2019, pp. 1-20, 2019, doi: $10.1155 / 2019 / 6470359$.

[2] C. M. G. Gussen, P. S. R. Diniz, M. L. R. Campos, W. A. Martins, F. M. Costa, and J. N. Gois, "A Survey of Underwater Wireless Communication Technologies," JCIS, vol. 31, no. 1, pp. 242-255, 2016, doi: 10.14209/jcis.2016.22.

[3] Z. Wang, S. Zhou, and Z. Wang, "Underwater Distributed Antenna Systems: Design Opportunities and Challenges," IEEE Commun. Mag., vol. 56, no. 10, pp. 178-185, 2018, doi: 10.1109/MCOM.2017.1601071. 
[4] S. I. Inácio et al., "Antenna design for underwater radio communications,” Ocean. 2016 - Shanghai, pp. 1-6, 2016, doi: 10.1109/OCEANSAP.2016.7485705.

[5] O. Aboderin, L. M. Pessoa, and H. M. Salgado, "Wideband dipole antennas with parasitic elements for underwater communications," Ocean. 2017 - Aberdeen, vol. 2017-Octob, pp. 1-6, 2017, doi: 10.1109/OCEANSE.2017.8084865.

[6] O. Aboderin, L. M. Pessoa, and H. M. Salgado, "Performance evaluation of antennas for underwater applications," 2017 Wirel. Days, WD 2017, pp. 194-197, 2017, doi: 10.1109/WD.2017.7918142.

[7] O. Aboderin, L. M. Pessoa, and H. M. Salgado, "Analysis of loop antenna with ground plane for underwater communications," Ocean. 2017 - Aberdeen, vol. 2017-Octob, pp. 1-6, 2017, doi: 10.1109/OCEANSE.2017.8084864.

[8] E. A. Karagianni, "Electromagnetic Waves under Sea: Bow-Tie Antenna Design for Wi-Fi Underwater Communications," PIER M, vol. 41, no. March, pp. 189-198, 2015, doi: 10.2528/PIERM15012106.

[9] Massaccesi and P. Pirinoli, "Analysis of antennas for underwater applications," 2017 11th Eur. Conf. Antennas Propagation, EUCAP 2017, pp. 1907-1910, 2017, doi: 10.23919/EuCAP.2017.7928763.

[10] W. L. Stutzman and G. A. Thiele, "Antenna Theory and Design”, vol. 23, no. 5. 1981.

[11] N. H. Moktar, W. I. Roseli, M. T. Ali, and R. A. Awang, "A study of distilled water and zamzam water as dielecric dense patch antenna at $5 \mathrm{GHz}$," Indonesian Journal of Electrical Engineering and Computer Science (IJEECS), vol. 15, no. 2, pp. 942-949, 2019, doi: 10.11591/ijeecs.v15.i2.pp942-949.

[12] R. H. Thaher and N. B. Hassan, "Design of p-shaped microstrip patch antenna for wireless communication systems," Indonesian Journal of Electrical Engineering and Computer Science (IJEECS), vol. 15, no. 2, pp. 861869, 2019, doi: 10.11591/ijeecs.v15.i2.pp861-869.

[13] Sabah and M. J. Frhan, "A new patch antenna for ultra wide band communication applications," Indones. J. Electr. Eng. Comput. Sci. (IJEECS), vol. 18, no. 2, p. 848-855, 2020, doi: 10.11591/ijeecs.v18.i2.pp848-855.

[14] R. Somaraju and J. Trumpf, "Frequency, Temperature and Salinity Variation of the Permittivity of Seawater," IEEE Transactions on Antennas and Propagation, vol. 54, no. 11, pp. 3441-3448, 2006, doi: 10.1109/TAP.2006.884290.

[15] H. Fabian, G. Mendez, C. Gac, and P. France, "High Performance Underwater UHF Radio Antenna Development," no. 1, pp. 2-6, 2011

[16] S. Jiang and S. Georgakopoulos, "Electromagnetic Wave Propagation into Fresh Water," J. Electromagn. Anal. Appl., vol. 03, no. 07, pp. 261-266, 2011, doi: 10.4236/jemaa.2011.37042.

[17] P. Debye, "Dispersion and Absorption in Dielectrics," J. Chem. Phys., vol. 9, no. 1913, p. 341, 1941.

[18] S. O. Nelson and S. Trabelsi, "Models for the microwave dielectric properties of grain and seed," Trans. ASABE, vol. 54, no. 2, pp. 549-553, 2011, doi: 10.13031/2013.36458.

[19] Palmeiro, M. Martín, I. Crowther, and M. Rhodes, "Underwater radio frequency communications," Ocean. 2011 IEEE - Spain, 2011, doi: 10.1109/Oceans-Spain.2011.6003580.

[20] T. D. De Paillette, A. Gaugue, E. Parlier, S. Dardenne, and A. S. Properties, "Antenna Design for Underwater Wireless Telemetry Systems," 2017 11th Eur. Conf. Antennas Propag., pp. 2251-2255, 2017, doi: 10.23919/EuCAP.2017.7928513.

[21] H. Zhang, D. Geng, G. Zhang, and T. A. Gulliver, "The impact of antenna design and frequency on underwater wireless communications," IEEE Pacific RIM Conf. Commun. Comput. Signal Process.-Proc., pp. 868-872, 2011, doi: 10.1109/PACRIM.2011.6033009.

[22] T. K. Mpountas and D. I. Kaklamani, "Bow-Tie Antenna for Underwater Wireless Sensor Networks," 2017 Int. Work. Antenna Technol. Small Antennas, Innov. Struct. Appl., pp. 323-326, 2017, doi: 10.1109/IWAT.2017.7915391.

[23] Pasya, H. M. Zali, M. Saat, M. T. Ali, and T. Kobayashi, "Buffer layer configuration for wideband microstrip patch antenna for underwater applications," 2016 Loughbrgh. Antennas Propag. Conf. LAPC 2016, vol. 3, no. 600, pp. 15, 2017, doi: 10.1109/LAPC.2016.7807577.

[24] H. Yoshida et al., "Underwater LF wave propagation study for positioning," Ocean. 2017-Aberdeen, vol. 2017October, no. Dvl, pp. 1-5, 2017, doi: 10.1109/OCEANSE.2017.8084829.

[25] U. M. Qureshi et al., "RF path and absorption loss estimation for underwaterwireless sensor networks in differentwater environments," Sensors (Switzerland), vol. 16, no. 6, 2016, doi: 10.3390/s16060890.

\section{BIOGRAPHIES OF AUTHORS}

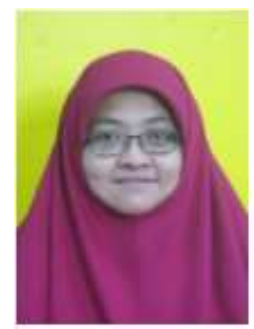

Siti Harliza Mohd Razali received the B. Eng. Degree (Hons.) from Universiti Kebangsaan Malaysia (UKM), Bangi, Malaysia in 1999 and M. Eng. Degree in Electrical-Electronics Telecommunication from Universiti Teknologi Malaysia (UTM), Johor Bahru, Malaysia in 2007. She is currently a Lecturer at Politeknik Sultan Salahuddin Abdul Aziz Shah (PSA), Shah Alam, Selangor, Malaysia and post-graduate student in UTMKL. Her current research interests include antenna, propagation and budget link for antennas that apply in underwater wireless communication system. 

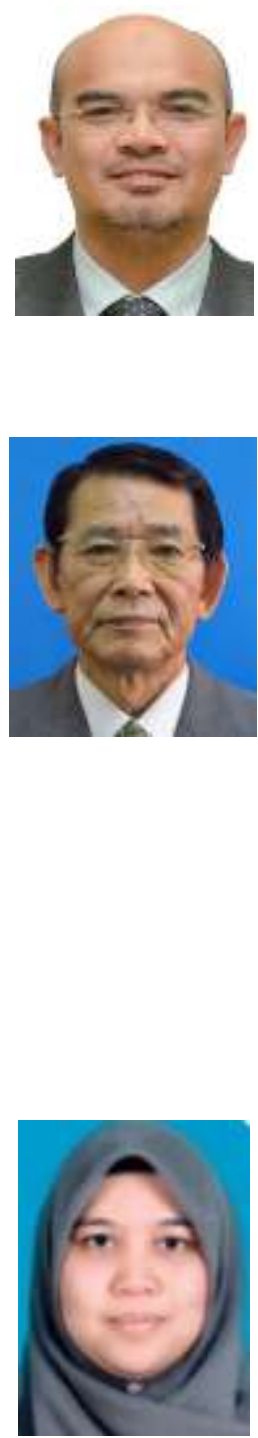

Assoc. Prof. Dr. Razali Ngah obtained his Bachelor in Electrical Engineering (Communication) from Universiti Teknologi Malaysia, Skudai in 1989, MSc in RF Communication Engineering from University of Bradford, UK in 1996 and PhD in Photonics from University of Northumbria, UK in 2005. Since 1989, he has been with the Faculty of Electrical Engineering, UTM, where he is currently a Senior Lecturer.Currently, he is an Associate Professor at Wireless Communication Centre (WCC), Faculty of Electrical Engineering, UTM Skudai. His research interests are Mobile Radio Propagation, Antenna and RF design, Photonics Network, Wireless Communication Systems and Radio over Fibre (RoF). Dr. Razali had published more than 50 technical papers for journal and international conferences. His current focus is on his research activity, internal audit committee of university and supervising Postgraduate and Undergraduate students.

Prof. Dr. Yoshihide Yamada received the B.E. and M.E. degrees on electronics from the Nagoya Institute of Technology, Nagoya, Japan, in 1971 and 1973, respectively, and the D.E. degree in electrical engineering from the Tokyo Institute of Technology, Tokyo, Japan, in 1989. In 1973, he joined Electrical Communication Laboratories, Nippon Telegraph and Telephone Corporation (NTT). Until 1984, he was involved in research and development of reflector antennas for terrestrial and satellite communications. From 1985 to 1993, he was involved on research and development of base station antennas for mobile radio systems. In 1993, he moved to NTT Mobile Communications Network Inc. (NTT DoCoMo). In 1995, he was temporarily transferred to YRP Mobile Telecommunications Key Technology Research Laboratories Co., Ltd. He was a Guest Professor with the Cooperative Research Center, Niigata University, and a Lecturer with the Tokyo University of Science, from 1996 to 1997. In 1998, he became a Professor with the National Defense Academy, Kanagawa, Japan. Since 2014, he has been a Professor with the Malaysia-Japan International Institute of Technology, Universiti Teknologi Malaysia, Kuala Lumpur, Malaysia. He is currently interested in very small antennas, array antennas, aperture antennas, and electromagnetic simulation of RCS. He received the Best Paper Award and the Best Tutorial Paper Award from the IEICE in 2013 and 2014, respectively. He is a Fellow Member of the IEICE and a Senior Member of the IEEE AP Society. He is also a member of the ACES. (Based on document published on 12 October 2017).

Ir. Dr. Kamilia Kamardin received her B.Eng. Electronic (Communications) from the University of Sheffield, U.K., in 2004 and obtained her M.Sc. in Information Technology (Data Communications and Networking) from Universiti Teknologi Mara (UiTM), Malaysia in 2007. She received her Ph.D. in Electrical Engineering (Communications) from Universiti Teknologi Malaysia (UTM), Malaysia in 2014. She spent 3 months at University of Bimingham, U.K., as a visiting Ph.D. student. She has previously served as a senior assistant researcher at TM Research and Development, Malaysia for 3 years. Currently she is a senior lecturer at Universiti Teknologi Malaysia, Kuala Lumpur. She serves under department of Computer Systems Engineering at Advanced Informatics School. Her research interests include antennas, wireless communication, wearable communication, body centric communication, metamaterials, wireless networking and computer systems engineering. 